\title{
A TRAJETÓRIA DA \\ INDUSTRIALIZAÇÃO NO BRASIL: \\ Pensamento industrialista, \\ MODERNIZAÇÃO E A FORMAÇÃO DA \\ OSSATURA DO ESTADO
}

Arthur de Aquino ${ }^{1}$

\begin{abstract}
Resumo
Esse texto trata da consolidação do projeto industrialista juntamente com a formação da ossatura do Estado brasileiro. A liderança de Simonsen caracteriza um momento sui generis na formação de uma consciência corporativa de classe entre os industriais, uma vez que esses superam o imediatismo conjuntural de suas demandas, em direção à elaboração ideológica de um projeto alternativo possível, rumo ao desenvolvimento econômico. 0 segmento industrialista aparece como produto histórico de uma contradição gerada dentro do complexo cafeeiro exportador; historicamente, portanto, o café gerou o seu contrário, a indústria. A preocupação central aqui consiste na consolidação da ideologia industrialista e sua passagem à projeto nacional frente à hegemonia do café, e cujo eixo argumentativo orbitou a "questão nacional" e a questão da modernização.
\end{abstract}

Palavras-chave: Roberto Simonsen. Industrialização. Pensamento Social Brasileiro.

\footnotetext{
${ }^{1}$ Mestrando em Ciência Política pela Unicamp. End. eletrônico: arthur.aquino@gmail.com Agradeço aos pareceristas anônimos da revista Mediações pelas valiosas contribuições a este artigo.
} 


\section{THE TRAJECTORY OF INDUSTRIALIZATION IN BRAZIL: INDUSTRIAL THOUGHT, MODERNIZATION AND FORMATION OF THE STATE STRUCTURE}

\section{Abstract}

This text deals with the consolidation of industrial design along with the structure formation of the Brazilian State. Simonsen's leadership now features a "sui generis" moment in forming a corporate class consciousness among industrialists, since they overcome the immediate economic situation of their demands toward the ideological elaboration of a possible alternative project, towards the economic development. The industrialist segment appears as a historical outcome of a contradiction generated within the coffee exporter complex, historically, thus, the coffee has generated its opposite, the industry. The central concern here is to consolidate the industrialist ideology and its transition to the national project in face of the coffee hegemony, and whose argumentative axis orbited the "national question" and the question of modernization. Key words: Roberto Simonsen. Industrialization. Brazilian Social Thought

\section{INTRODUÇÃO: REVOLUÇÃO DE 1930 (?) E O EIXO CRÍTICO DA MODERNIZAÇÃO BRASILEIRA}

$\mathrm{H}$ á um extenso debate na bibliografia sobre a importância e significado de 1930 como momento crítico da modernização e construção da nação. A importância com relação à análise desse período em especial consiste em entender o eixo pelo qual se desdobrarão os processos de modernização "pelo alto" os quais constituirão a construção do colosso do Estado brasileiro entre 1930-1960. Esse processo será caracterizado por luta pela hegemonia em sentido gramsciano, entre diferentes projetos políticos. 0 industrialismo/desenvolvimentismo conquista a hegemonia "ideológica" no período 1930-1960 porque a própria industrialização se tornou um valor na medida em que se tornou prioridade para a nação. Muito embora essa hegemonia no pós-1930 não se completará em hegemonia política, perdendo nesse ponto para o café, seguramente até 1950 (BAER, 1966; CARONE, 1982; DINIZ, 1977).

Boris Fausto argumenta de maneira mais contundente que o Estado pós1930 cresceu elevadamente por conta do vazio de poder provocado em 1930. Essa autonomia que o Estado conseguiu frente às classes o permitiu tomar lugar de árbitro na sociedade e estabelecer um estado de compromisso. Fausto concorda 
com Cardoso com relação ao comportamento pouco organizado da burguesia industrial brasileira até a década de 1950 (FAUSTO, 1989, p. 47-50). Cardoso ao elaborar esse estudo sobre a mentalidade dos "capitães de indústria" e dos "homens de empresa" não considerou as diferenciações internas da vertente industrialista.

Draibe sugere que a Grande Depressão (1929-1933) somada à crise política a partir de dentro do sistema político brasileiro repercutiram de maneira negativa mesmo para o complexo cafeeiro, de modo que o advento do Estado Leviatã consistiu numa revolução "pelo alto" (DRAIBE, 1985, p. 22). Entretanto uma diferença fundamental com Fausto: Draibe leva seriamente em consideração que os industriais representaram ainda durante a Era Vargas uma força política expressiva, de modo que sua atuação política é quem teria dado respaldo a uma organização autoritária e tecno-burocrática, progressivamente forjada entre 19451964. Draibe precisou admitir que mesmo a autonomia relativa do Estado foi seriamente limitada por fatores desencadeados pelo seu próprio funcionamento: Ao hierarquizar interesses sociais através de mutações ocorridas dentro do "colosso", surgem conselhos e ministérios que abrigam diferentes grupos sociais em luta, portadores de diversos projetos de sociedade. 0 Estado acabou sendo atravessado por essas lutas quando introjetou os conflitos para dentro de si, na tentativa de media-los, ao adotar o modelo de organização corporativa de si mesmo e da sociedade (DRAIBE, idem, p. 36-39, 43-45).

Lourdes Sola, por outro lado, tende a ver a figura do "técnico" como eixo da produção e legitimação de um tipo especial de avaliação e diagnóstico. As arenas decisórias do Estado vão progressivamente ficando mais elitizadas entre 1945-1964. Sola prioriza a ação dos intelectuais na vida política, assim como a importância das idéias no processo ao supor a autonomia das instituições, enfatizando as lutas de caráter paradigmático/ideológico.

Tanto Sola quanto Draibe mostram de maneira bastante clara como 0 Estado varguista abriu terreno para a consolidação de uma tecnoburocracia que se construiria nas décadas seguintes. Ao mediar relações de classe, o Estado-leviatã 0 fazia a partir de comissões técnicas cujos pareceres seriam decisivos nos processos de tomada de decisão. Mesmo Renato Boschi compartilha de visão semelhante. Para esse autor o ponto de vista dos intelectuais é locus da prática burguesa e do debate institucional em diferentes momentos. Por ser um sistema elitista, o sistema político brasileiro guardaria uma relação muito forte entre a produção intelectual e os arranjos políticos, daí a importância do estudo dos intelectuais (BOSCHI, 1979, p. 56). Entretanto, sugere que uma política industrial embrionária vem 
da formação de um aparato mais complexo dentro da esfera estatal, quando da necessidade de controle por parte do Estado dos setores chave do desenvolvimento econômico. Por isso é que os industriais, ao tomarem consciência da importância desse controle, passariam a se organizar em âmbito nacional, numa tentativa de integrar as diversas federações regionais já existentes. (idem, p. 64)

Boschi (Idem, p. 65-67), apesar de seguir a rota segura da tendência reativa dos industriais frente ao processo político dos anos 1930 como determinante de seu projeto político, sugere que o apoio dos industriais ao golpe de 1937 foi advindo da mentalidade corporativista amadurecida intelectual e teoricamente no período. Também explica esse apoio o próprio fato dos industriais virem participando ativamente da vida política nacional desde os anos 1920 e 1930, assim presentes na luta política o suficiente para disputar a hegemonia política em dois momentos cruciais: Constituinte de 1934 e o apoio ao golpe do Estado Novo em 1937.

Eli Diniz também concorda que houve uma situação de Estado de compromisso, autônomo em sua lógica interna, mas atravessado pelas lutas entre agricultura e indústria. Por outro lado, a autora reconhece que a entrada da burguesia industrial nos esquemas tradicionais de aliança política foi problemática por conta da forte resistência dos setores tradicionais ligados à agricultura de exportação. Isso porque tal inserção faria emergir novas demandas, que por sua vez reordenariam as prioridades e diretrizes do conjunto econômico e social (DINIZ, 1978, p. 226).

Entretanto Diniz nega que houve, mesmo antes ou depois de 1930, elaboração político-intelectual do empresariado industrial, no sentido de construção ideológica pretensamente hegemônica em acepção gramsciana; os industriais para a autora permanecem no imediatismo corporativista de suas demandas (idem, p. 241). A concepção da autora é contrastante com a formulação de um projeto político industrial que, ainda fosse cheio de impasses e dificuldades, estava sendo forjado, mais contundentemente no pós-1930.

Apesar de suas diferenças internas esse grupo de autores (DINIZ, 1978; BOSCHI, 1979; DRAIBE, 1985; SOLA, 2000; FAUSTO, 1989; CARDOSO, 1964) guarda uma característica significativa: todo(a)s assumem, em maior ou menor medida, 1930 como crise de hegemonia, levando a um vazio de poder que culmina no Estado de compromisso.

Com relação à hipótese de "vazio de poder" em 1930 e a subseqüente autonomia do Estado, essa hipótese tende a esconder as organizações de interesse 
e formulações de projetos políticos pretensamente hegemônicos antes de 1930. Diniz (op.cit), por exemplo, admite que houve organização de interesses entre os industriais antes de 1930, mas não que uma ideologia orgânica e pretensamente hegemônica estivesse se construindo junto com o ator empresariado. Nesse sentido seria interessante visitar uma corrente do debate que lida com a hipótese contrária, qual seja: de que o processo de modernização em marcha no Brasil antecedeu a 1930, de modo que não se deveria fixar nesse ano o marco essencial para tal ruptura, mas sim reconhecer um processo/projeto de modernização brasileira já em curso. 0 que diferenciaria os projetos industriais antes e depois de 1930 seria uma questão de elaboração político-intelectual: enquanto o pensamento industrial até 1930 não supera o âmbito meramente econômico-corporativo, o pensamento feito pós-30 dentro do complexo CIESP/FIESP (BIANCHI, 2004) e nos Congressos industriais dos anos 1940, tenderam a atingir uma dimensão de pretensa hegemonia.

Decca coloca mesmo em questão se "1930" deveria servir como parâmetro, visto que 0 movimento que se seguiu foi empreendido pela aliança agrárioindustrial, mas com um projeto e apoio já colocados pelo Bloco Operário e Camponês (BOC). Enquanto o BOC tendia a colocar a classe operária como participante ativa do processo, PD, PRP e tenentismo tinham em comum a oposição a qualquer idéia de uma alteração radical nas estruturas da sociedade. 0 PD e os tenentes incorporaram o tema da revolução, sem assumi-lo de maneira explícita, mas o fizeram para se aproximar do BOC e tenentes.

Em 1928, concomitantemente à cisão dos industriais da Associação Comercial de São Paulo (origem do CIESP), as convulsões sociais fizeram com que os industriais formulassem um projeto político global, que pudesse orientar de ponta a ponta o conjunto social. Assim, apesar do BOC ter participado ativamente do movimento de 1930, perdeu a dianteira do processo; de modo que 1930 consistiu basicamente numa revolução "pelo alto"; ainda que a participação ativa anterior do BOC tivesse sido de fundamental importância, ele foi silenciado.

Aqui a posição dos industriais é ambígua e vacilante. Fazem oposição ao golpe de 30, mas porque apoiavam a política cambial de Washington Luiz. Um marco importante para o seu apoio ao regime de Getúlio será 1934 com a criação do Conselho Nacional de Política Industrial e Comercial (CNPIC), o qual abrigará membros da indústria em seus quadros consultivos e deliberativos, entre eles o próprio Roberto Simonsen (VIEIRA, 1988, p. 47-52). 
Ângela Castro Gomes também confere importância mais ao pacto acertado em 1930 do que ao arbítrio de um Estado-demiurgo. As questões relacionadas à indústria tomariam novo fôlego, decorrente de um conjunto de demandas oriundas de um novo compromisso político, acertado em 1930 (GOMES, 1979, p. 201). Esse compromisso envolveria as classes médias e trabalhadoras dos centros urbanos, e surgiria em contraposição à hegemonia do café. Um dos pontos críticos da resistência à hegemonia cafeeira foi justamente a crítica dos setores urbanos e industriais com relação à política governamental de valorização do café, a "questão social", e a questão cambial.

Lima faz a crítica a Decca e Gomes, sugerindo que o projeto político industrial é mais antigo que as marcações em 1930 (Gomes) e 1928 (Decca), e argumenta que nas décadas de 1910 e 1920 os industriais do ramo têxtil elaboravam um projeto político, frente a três grandes lutas com a classe operária: lei de acidentes de trabalho (1919) lei de férias (1925), e código de menores (1927). 0 parecer dos industriais era sempre seguido de uma contraproposta, e no caso mesmo da lei de acidentes de trabalho, foram eles que ajudaram a constituir a letra da lei. 0 mesmo não aconteceria com a lei de férias e o código de menores, onde os industriais argumentariam pelo encarecimento da produção. Ao conjunto de respostas condicionadas pelos seus interesses, Lima chamou de projeto politico industrial; o qual seria resultado das posições que a fração de classe burguesaindustrial tomara no decorrer das lutas em torno da políitca social junto aos trabalhadores.

Concomitante com a sua própria formação e desenvolvimento, o segmento industrialista constrói ideologia e projeto alternativo de futuro para a sociedade. Esse processo seria difícil e descontínuo, mesmo se pensarmos os desencontros entre base e direção do movimento industrialista. Mas é a partir dos seus movimentos que podem ser apreendidos os contornos mais ou menos nítidos de um projeto político.

\section{Projeto Político IndUSTRIALISTA: Proposição?}

Mas, então, seria o projeto político industrialista meramente reativo a choques de interesse junto ao BOC e demais lideranças operárias em conjunto? Qual seria a dimensão propriamente propositiva do projeto político industrialista?

Gomes $(1978$, p. 308, 312) já havia levado a cabo essa hipótese quando afirmou que o comportamento da burguesia pós-1930 é reativo, porque não 
usa fundamentalmente seu poder de iniciativa, mas sim seu poder de veto frente às reivindicações trabalhistas. Entretanto, nessa ação reativa é que a burguesia industrial conseguiria de acordo com a autora superar suas divergências internas e emergir como um "bloco". A burguesia urbana não rejeitaria o intervencionismo de Estado a princípio, mas sim o condicionaria. A legislação sindical, por exemplo, estava ela mesma no centro da construção de um novo modelo de Estado, centrado na "paz social".

De fato a colaboração e compromisso de classes é de importância significativa no pensamento industrialista pós-1930. Entretanto ele é parte desse pensamento, de modo que uma dimensão propriamente propositiva teria que levar em conta além das relações capital/trabalho também as relações internacionais, a organização da produção, a questão dos direitos, a escolha ou não pelo regime democrático, e o significado da nação.

Em 1928 Roberto Simonsen publica Orientação Industrial Brasileira, onde antecipa de maneira bastante rudimentar questões que seriam levantadas apenas nos anos 1950 pelo pensamento cepalino. Colocou em questão que a independência econômica depende de um regime aduaneiro o qual desonere a importação de matéria prima e onere a importação de manufaturados que tenham um similar nacional. Protegendo a indústria, a produtividade aumenta e com ela o valor dos salários. Um regime cambial apropriado poderia garantir ao Brasil nichos de mercado no exterior, o que melhoraria o balanço de pagamentos e daria novo impulso à reprodução de capital. Dessa maneira, seria necessário antes de tudo capitalizar a economia nacional, o que significa desenvolver o próprio capitalismo no Brasil. Essa dimensão da reflexão Simonseana aponta para 0 caráter propositivo e projetivo da idéia de construção da nação.

Dessa maneira, não se entende a Era Vargas e as lutas políticas desencadeadas nela se admitindo 1930 apenas como "ruptura", mesmo porque o processo de modernização já estava em marcha. Com relação ao caráter do projeto industrialista, reativo/propositivo, aquele binômio não pode ser entendido em termos absolutos. Na verdade o "projeto" tanto não pode ser apenas proposição como também não apenas reação; mas certamente a proposição é um dos lados da moeda. Dessa maneira é que não julgo aceitável falar no projeto industrialista forjado na Era Vargas, principalmente no pensamento de Roberto Simonsen, como meramente reativo. Sobre o pensamento de Simonsen e a articulação ideológica do segmento industrialista é que vamos nos deter agora. 


\section{O Pensamento de Roberto Simonsen}

Existe atualmente amplabibliografiasobre Roberto Simonsen. Basicamente duas abordagens principais: as que dividem a obra do autor em fases de elaboração intelectual (CEPEDA, 2004; VIEIRA, 1988) e as que tratam da obra como uma unidade continua (CAETANO, 1994; MAZZA, 2004; FANGANIELLO, 1970). Todos os estudos levam em consideração as pretensões de Simonsen em torno da construção da nação; destacam em maior ou menor medida a interpretação de Simonsen sobre o papel e o lugar da classe trabalhadora, cujas demandas deveriam incluir-se no projeto político.

0 industrialismo consistiu na ideologia que deu consistência intelectual a essa ordem de coisas, assim como constituiu um projeto político hegemônico e global. Seu locus por excelência foi o CIESP, e seu principal intelectual, Roberto Simonsen. Por se tratar de um autor de fases, cada uma delas possui tensões e questionamentos internos. Em um sentido geral podemos colocar o sentido dessa elaboração intelectual como a superação da ambigüidade que sofre entre intervencionismo e liberalismo - industrial demais para suportar o peso do livremercado, empresário demais para suportar a idéia de intervenção do Estado em seus negócios.

Numa primeira fase os escritos entre 1912-1928 consistem fundamentalmente em textos de ordem técnica, entre os quais sobre o calçamento de Santos e A Construção de Quartéis para o Exercito.

Alguns textos da segunda fase são As Crises no Brasil (1930), As Finanças e a Induistria (1931), ’̀ Margem da Profissão (1931), Ordem Econômica, Padrão de Vida eAlgumas Realidades Brasileiras (1934), eAspectos da Politica Econômica Nacional (1935). Simonsen acreditava que as crises nacionais eram decorrentes das crises de ordem econômica, relacionadas ao câmbio e a "saúde" da moeda. Entendia que o principal motivo para tais distúrbios era a inépcia dos tomadores de decisão com relação a política econômica. Nesse sentido já apontava nessa fase a necessidade da figura do técnico em economia em acordo com o "homem de negócios" tanto no entendimento dos problemas quanto nas tomadas de decisão. Mas nessa fase Simonsen ainda não havia resolvido aquela esquizofrenia intelectual entre liberalismo e intervencionismo.

Uma terceira fase é inaugurada em 1937 com História Econômica do Brasil (1500-1820), onde Simonsen se descola do liberalismo e resolve aquela contradição de que padece seu pensamento. Em História Econômica faz um 
mapeamento e sistematização do processo de formação econômica do Brasil colônia. Esse texto foi sistematizado a partir de suas aulas na Escola Livre de Sociologia e Política de São Paulo. Consistiu num amplo levantamento de dados, assim como uma rica interpretação deles. Argumentou pela necessidade de se cruzar diferentes ciências sociais e humanas na compreensão do processo histórico, político e econômico brasileiro (sociologia, economia, geografia, história). São dessa fase também A Evolução Industrial no Brasil (1939), Recursos Econômicos e Movimento das Populações (1940), Os Elos da Indústria (1944), e os pareceres submetidos ao CNPIC e CPE nos quais esteve em Controvérsia com Eugenio Gudin.

Foi Vera Cepêda (2004, p. 322) quem percebeu que a relação entre a crítica de Simonsen ao plano Marshall e o conjunto dos textos onde ele fez a defesa do planejamento antecipou o pensamento cepalino em sua essência.

De acordo com a autora, a ligação entre os textos de Simonsen sobre planejamento e a crítica ao plano Marshall levaram a uma antecipação de todos os argumentos cepalinos, principalmente nos textos escritos entre 19431948. Para Simonsen, uma vez que a posição dos diferentes países é desigual em termos de capacidade produtiva e tecnológica, há uma clivagem entre países supercapitalizados (produtoresindustriais) esubcapitalizados (agro-exportadores). As trocas são desiguais, uma vez que a natureza da produção determina o valor agregado e, portanto, os termos de troca. A tendência ao monopólio pelos países supercapitalizados, juntamente com a especialização das economias nacionais dentro da divisão internacional do trabalho, leva ao aprofundamento dessa dependência. 0 escape para esse círculo vicioso seria: um crescimento "para fora", no sentido de abandono das teses liberais ortodoxas do libre-cambismo nas trocas internacionais; e "para dentro", no sentido de adotar o planejamento econômico como método, com vistas a organizar e disciplinar as forças produtivas, e com isso atingir o desenvolvimento econômico e social (CEPÊDA, 2004, p. 322-323).

Além disso, há um consenso na literatura especializada quanto à influência que List e Manoilescu exerceram no pensamento de Simonsen. Para List, diferentes países têm diferentes trajetórias históricas de modo que o desenvolvimento da indústria na Alemanha do século XIX não poderia acontecer sem o protecionismo; List acreditava que o protecionismo era uma condição absolutamente temporária enquanto a indústria nacional não pudesse competir em condições razoáveis com o mercado internacional. Simonsen defenderia que o Estado brasileiro 
deveria proteger a incipiente indústria nacional enquanto ela não pudesse concorrer de maneira equilibrada com a grande indústria dos países centrais. Concomitantemente, deveria o mesmo Estado promover políticas industriais de incentivo à inovação e desenvolvimento tecnológico.

Também é notável a influência de Manoilescu, que foi à época o autor referencial ao que toca a doutrina corporativista de organização do Estado e da sociedade. A corporação seria definida pela função nacional que ela exerce dentro da sociedade nacional, a qual consistiria num conjunto orgânico de corporações. Sua existência supera em importância a existência do indivíduo (MANOILESCU, 1938, p. 48). Heterogênea em sua composição, a corporação é homogênea em sua finalidade; as corporações são formadas de acordo com a função nacional que desempenham, tal como função industrial. Entretanto Manoilescu argumenta que esse tipo de organização social não pode ser confundido com a mera representação profissional parlamentar porque a doutrina do corporativismo consiste numa forma de organização completa da sociedade, ultrapassando o âmbito meramente econômico. Notáveis são, portanto, os elementos da paz social e da concepção orgânica da sociedade no pensamento de Manoilescu. Esses dois elementos primordiais serão decisivos também no pensamento de Roberto Simonsen.

\section{INDÚSTRIA E AGRICULTURA EM UNIDADE E CONTRADIÇÃO}

$\mathrm{Na}$ interpretação clássica de Celso Furtado, presente em Formação Econômica do Brasil, o Estado ao manter uma política de proteção aos preços do café acabou gerando de maneira não intencional a capitalização do impulso industrializante nos anos 1930. Isso porque ao manter os preços do café as inversões foram canalizadas tanto para as agriculturas satélites ao café quanto à própria formação industrial baseada na montagem do complexo cafeeiro, consistindo num keynesianismo antecipado.

Todavia, a modernidade brasileira seria um processo problemático dada a presença de uma dualidade estrutural, esquema teórico colocado de maneira exemplar em Desenvolvimento e Subdesenvolvimento, onde Furtado mostra a singularidade do caso brasileiro e latino-americano. Na periferia houve uma demanda plural e reprimida, que seria atendida em grande parte pelas importações. É a partir de 1930, com o progressivo e paulatino colapso da hegemonia cafeeira, que se forma um núcleo industrial para atender essa procura preexistente de manufaturas. 
Existiria formação tendencial de poupança nas economias periféricas mais complexas. 0 problema é que mesmo essas economias têm dificuldade de manter sua capacidade para importar, elemento crucial para adquirir bens de equipamento, fator indispensável para garantir a produtividade, o que mantém o equilíbrio da balança de pagamentos. A queda da capacidade de importar traz consigo duas tendências: corrida às importações de bens duráveis e não-duráveis de caráter supérfluo; e o investimento na indústria de construção civil. Ambas comprometem o crescimento econômico porque não realimentam o sistema produtivo com a formação de novos capitais fixos que garantam a reprodução de bens de capital em geral.

A superação da condição de subdesenvolvimento para Furtado depende da expansão desse núcleo industrial formado a partir dos choques pelo lado da oferta, provocados pela Grande Depressão de 1929. Com o colapso da capacidade para importar, a industrialização atende às necessidades da demanda, cuja expansão coincide com a integração da sociedade nacional enquanto sociedade capitalista. A estrutura social que Furtado pensa nesse arranjo compreende três instâncias principais: um setor da economia basicamente de subsistência; um setor mercantil-exportador; e um setor industrial, cujo crescimento vinha sendo pautado na substituição de importações.

Esse processo de integração é lento e problemático, pois implica que 0 núcleo industrial absorva a economia de subsistência, a qual - além de resistente a mudança - atravanca o desenvolvimento. Assim, o desenvolvimento volta a esbarrar nos impasses criados pelo Brasil arcaico, o qual permite a existência firme e teimosa da dualidade estrutural.

Entretanto, recuperar a trajetória das relações entre café e indústria, ou mesmo entre agricultura e indústria, na perspectiva dualista nos faz cair num problema fundamental: como explicar a presença de tal dualidade como estrutural, uma vez que indústria e agricultura possuem uma relação forte entre si? Foi o próprio Furtado quem observou que da política de proteção ao café vieram às condições de formação de capital para a indústria, assim como o café conseguia redistribuir o capital entre as agriculturas satélites integradas ao complexo exportador. Por outro lado, mesmo a agricultura como setor mais geral da economia brasileira esteve presente no I Congresso de Economia: algodão, maniçoba, açúcar, cacau, e cerealista. Notadamente o café não estava representado, uma vez que tanto os outros segmentos agrícolas como a indústria eram francamente contra a continuidade da proteção cafeeira. 
Mas seria um dualismo estrutural café-indústria? Para falar em dualismo estrutural é necessário lidar com uma envergadura ampla da sociedade: a dualidade é arcaico/tradicional x moderno/industrial, e não apenas dois segmentos da economia, apesar da ampla importância deles. Mesmo assim não seria razoável pensar um dualismo indústria-café, porque ao passo que ambos estavam em conflito, também estavam em complementaridade.

Outra vertente do debate prefere lidar com uma unidade orgânica e contraditória entre café e indústria. Francisco de Oliveira e João Manuel Cardoso de Mello rejeitam a tese dualista demonstrando que a modernização como processo dependeu e mesmo se alimentou do arcaico de modo que não haveria cisão, mas continuidade, frente ao fato de que as forças que conduzem essa modernização na verdade transformam o sistema na finalidade de conservá-lo.

De acordo com João Manuel Cardoso de Mello (1988, p. 100, 104), a burguesia cafeeira foi a matriz social da burguesia industrial. A burguesia do café se motivou a investir na indústria pela baixa dos salários no momento de auge do café, assim como pelas medidas de proteção e incentivo aos segmentos da indústria. Esse processo foi conflitivo e contraditório visto que o padrão de acumulação industrial foi impulsionado e limitado pelo café ao mesmo tempo. Esses impasses inerentes à condição retardatária da indústria decorrem do próprio caráter retardatário do capitalismo no Brasil.

Maria Sylvia de Carvalho Franco já havia sugerido que práticas econômicas pré-capitalistas eram remanescentes da dificuldade imensa que passou a gênese do capitalismo no Brasil, o que decorreu da não proletarização dos "homens-livres" na sociedade escravocrata, no século XIX. Decorreu disso a ausência de uma mentalidade capitalista e uma ordem ético-juridica impessoal e racional, fator importante na persistência crônica de um sistema pré-capitalista de produção. Cardoso de Mello atribui essa ausência como fator preponderante para o caráter retardatário do capitalismo brasileiro. Por outro lado, Mello e Francisco de Oliveira mostram como não apenas os salários estagnaram no período de industrialização acelerada (1956-1961) como a renda real mesma caiu proporcionalmente no período, o que mostra que a industrialização não apenas não dividiu o "bolo" como 0 aumento da renda resultou também em sua concentração.

0 processo problemático de consolidação da sociedade de classes no Brasil legou o caráter retardatário do nosso capitalismo. Essa condição acarretou 0 caráter tardio do processo de industrialização. Isso porque decorreu do processo singular de formação do lócus econômico a unidade entre café e indústria, e por 
vários motivos. A imigração subvencionada massiva, iniciada nos anos $1880 \mathrm{com}$ a finalidade de deprimir os salários (SILVA, 1978, p. 80; STOLCKE, 1986 p. 42-45), gerou uma massa miserável de imigrantes, e impulsionou o êxodo rural, gerando um exército industrial de reserva nos grandes centros urbanos. Existe uma corrente significativa na literatura especializada sobre a importância da expansão cafeeira e o processo de industrialização, pois ambos estão em ciclo conjunto (SILVA, 1978; MELLO, 1988; STOLCKE, 1986; CANO, 1998, p. 25, 273; OLIVEIRA, 1978).

0 capital cafeeiro em sua robusta expansão gerou a sua própria negação, ao possibilitar os alicerces da indústria, que por sua vez teve ampla capacidade responsiva com relação à crise de 1929 (MELLO, 1988, p. 106-107; DEAN, 1976, cap. I). Entre 1933-1955 houve industrialização restringida por conta da fragilidade das bases técnicas e financeiras do eixo de acumulação, o qual cada vez mais migra da agricultura para a indústria. 0 problema aqui tanto é a incapacidade produtiva de crescer a frente da demanda, quanto o atraso crônico infra-estrutural e tecnológico, decorrente da industrialização retardatária.

\section{A voz dos IndUSTRIAIS: o I CONGRESSO BrasileIRo DE ECONOMIA}

A leitura do Congresso Brasileiro de Economia de 1943 é necessária para o entendimento da formação de uma consciência corporativa de classe por parte dos industriais do período. Estava organizado em oito comissões técnicas e uma de redação. Forma uma tríade com o Congresso Brasileiro da Indústria (São Paulo, 1944) e a Conferência das Classes Produtoras (I CONCLAP, Teresópolis, 1945).

Todavia, tem importância singular nessa tríade. É o primeiro dos três, e foi o que admitiu maior amplitude de influências, e portanto onde a pretensão de superar o âmbito econômico-corporativo em direção ao grupo social mais amplo, foi maior. Estavam representados em 1943: o Estado; as agriculturas satélites (mas não o café, notadamente) que faziam oposição a proteção cafeeira; os liberais, notadamente Gudin, Jurandyr Pires Ferreira e Hugo Hamman; a corrente industrialista, com representantes de todo país.

Entretanto, o Trabalho não estava representado, o que demonstra obstáculo notável à constituição de um projeto político pretensamente hegemônico, e isso porque a rede de alianças precisaria ser de ampla envergadura - ainda que a hierarquização de prioridades fosse $a$ industrial, e apresentada como universal ao conjunto da sociedade. Mesmo nesse set de representações a formação de alianças 
já seria problemática, o que as discussões no Congresso em torno da questão da inflação evidenciariam.

0 Congresso foi o locus de elaboração político-intelectual da corrente industrialista a um difícil rumo ao projeto industrialista de sociedade. Existia um hiato evidente entre direção e base do movimento industrialista: na direção do movimento, ideologia e projeto industrialista possuem elaboração políticointelectual notável em Roberto Simonsen, Daundt D'Oliveira, Euvaldo Lodi, entre outros; na base, os industriais ainda sofriam de uma verdadeira "esquizofrenia" intelectual, pelos liberais que eram por um lado, e a proteção que queriam do Estado, por outro.

Entretanto, há no I Congresso de Economia a formação de uma agenda de reivindicações bastante coesa, e mesmo formas bastante nítidas do que os industriais entendiam por um projeto nacional. Dentre as recomendações do Congresso ao governo: mudança do código de minas e de águas de 1934, criação de um banco central e assistência do Estado para com os industriais, assim como proteger o capital privado nacional. Uma importante vitória de Simonsen também foi convencer os industriais da "necessidade" da organização corporativista da sociedade e do Estado, ponto esse fundamental, porque dependeria dele formulação e implementação do planejamento econômico - este último condição para 0 crescimento industrial planejado e acelerado.

As relações de forças políticas (GRAMSCI, 1978a, p.49-51) entre os industriais com muita dificuldade vinham se desenvolvendo para além da dimensão econômico-corporativa. Numa das sessões do plenário onde se discutiu - e estavam Gudin e Simonsen presentes - o problema da inflação, chegou-se a um consenso de que o excesso de meios de pagamento em circulação é quem deveriam ser absorvidos. A proposta da Comissão de Redação e dos industriais foi em prol de uma modalidade de absorção de meios de pagamento através da venda de bônus e títulos ancorados em apólices de exportação. A proposta da Comissão Técnica liderada por Gudin propôs praticamente a taxação dos "lucros extraordinários". Ainda que nas duas propostas houvesse pelo menos a intenção de usar o dinheiro arrecadado na importação de bens de capital para a indústria, os industriais votaram pela primeira proposta, que era reconhecidamente fraca e voluntarista, mas os industriais não queriam ceder parte dos seus lucros em prol da montagem da indústria pesada.

Apesar disso, um importante passo foi dado no pensamento industrial brasileiro. A base do movimento industrialista chegou a um consenso em torno 
da identificação entre indústria e civilização, de modo que foi recomendada a colonização do binterland, pautada em estudos de geografia econômica. Esses estudos privilegiaram a turfa, a hulha e o petróleo, com vistas à indústria pesada. 0 crescimento industrial planejado e acelerado foi assumido e difundido como valor patriótico e nacionalista, e - juntamente com a aspiração corporativista seria o legado ideológico nas décadas seguintes.

\section{CONSIDERAÇÕES FINAIS}

A construção da ossatura do Estado brasileiro, cujo período nodal é 19301960 (DRAIBE, 1985), constituiu processo problemático e disruptivo porque foi atravessado por lutas e distensões. Dentro dessa forte luta pela hegemonia a questão nacional jogou um papel central nos debates e disputas, de modo que as correntes ideológicas que representavam diversos interesses de classes e frações de classe eram proponentes de projetos alternativos de futuro para o conjunto, sempre tentando lhe impor direção intelectual, moral e política.

Entre as correntes principais, encontram-se desenvolvimentismo versus liberalismo. A gênese do desenvolvimentismo no Brasil certamente esteve no pensamento de Roberto Simonsen, de modo que o I Congresso Brasileiro de Economia jogou papel importante no processo, pois foi lá que o projeto industrialista se consolidou, o que legaria para as décadas seguintes a organização corporativista da sociedade e do Estado, o advento da tecnoburocracia estatal, assim como impor ao conjunto da sociedade a industrialização como um valor. 0 desenvolvimentismo dos anos 1950/1960 foi a coroação do êxito do industrialismo em hierarquizar as prioridades do conjunto social, universalizando valores que eram seus para todo o conjunto social. Notadamente, o desenvolvimentismo identificou a industrialização com o próprio desenvolvimento.

\section{REFERÊNCIAS}

BAER, Werner. Industrialização e desenvolvimento econômico no Brasil. Rio de Janeiro: FGV, 1966.

BIANCHI, Álvaro. 0 ministério dos industriais: A FIESP na crise das décadas de 1980 e 1990. Tese de Doutorado, Ciência Política, Instituto de Filosofia e Ciências Humanas, Universidade Estadual de Campinas, 2004. 
BOSCHI, Renato. Elites industriais e democracia: hegemonia burguesa e mudança política no Brasil. Rio de Janeiro: Graal, 1979.

CAETANO, Coraly Gará. Desvendando mistérios: Roberto Simonsen e a luta de classes. Tese de Doutorado, História, Instituto de Filosofia e Ciências Humanas, Universidade Estadual de Campinas, 1994.

CANO, Wilson. Raizes da concentração industrial em São Paulo. Campinas: IE/ Unicamp, 1998.

CARDOSO, Fernando Henrique. Empresário industrial e desenvolvimento econômico do Brasil. São Paulo: Difusão Européia do Livro, 1964.

CARDOSO DE MELLO, João Manuel. O capitalismo tardio. São Paulo: Brasiliense, 1988.

CARONE, Edgar. O pensamento industrial no Brasil (1800-1945). São Paulo: Difel, 1977.

. A Terceira República (1937-1945). São Paulo: Difel, 1982.

CEPÊDA, Vera A. Roberto Simonsen e a formação da ideologia industrialista no Brasil: limites e impasses. Tese de Doutorado, Ciência Política, Faculdade de Filosofia, Letras e Ciências Humanas, Universidade de São Paulo, 2004.

I CONGRESSO BRASILEIRO DE ECONOMIA. Anais. Tomos I, II, III Rio de Janeiro: Associação Comercial do Rio de Janeiro, 1943, 1944, 1946.

DEAN, Warren. A industrialização de São Paulo. São Paulo: Difel, 1976.

DECCA, Edgar Salvatore de. O silêncio dos vencidos. São Paulo: Editora Brasiliense, 1988.

DINIZ, Eli. Empresário, Estado e capitalismo no Brasil: 1930-1945. Rio de Janeiro: Paz e Terra, 1978.

DRAIBE, Sonia. Rumos e metamorfoses: Estado e industrialização no Brasil (1930/1960). Rio de Janeiro: Editora Paz e Terra, 1985.

FANGANIELLO, Helena. Roberto Simonsen e o desenvolvimento econômico. São Paulo: FEA/USP, 1970.

FAUSTO, Boris. Revolução de 1930: história e historiografia. São Paulo: Editora Brasiliense, 1988.

FRANCO, Maria Sylvia de Carvalho. Homens livres na ordem escravocrata. São Paulo: Ática, 1974. 
FURTADO, Celso. Desenvolvimento e subdesenvolvimento. Rio de Janeiro: Civilização Brasileira, 1968.

. Formação econômica do Brasil. São Paulo: Companhia Editora Nacional, 1998.

GRAMSCI, Antonio. Maquiavel, a política e o Estado moderno. $3^{\circ}$ edição. Rio de Janeiro: Civilização Brasileira, 1978a.

. Os Intelectuais e a Organização da Cultura. $2^{\circ}$ edição. Rio de Janeiro: Civilização Brasileira, 1978b.

GOMES, Angela Maria de Castro. Burguesia e trabalho: política e legislação social no Brasil (1917-1937). Rio de Janeiro: Editora Campus, 1979.

LIMA, Marcos Alberto Horta. Legislação e trabalho em controvérsia historiográfica: o projeto político dos industriais brasileiros. Tese de Doutorado, História, Instituto de Filosofia e Ciências Humanas, Universidade Estadual de Campinas, 2005.

LIST, Friedrich. Sistema nacional de economia política. São Paulo: Nova Cultural, 1989.

MANOILESCU, Mikail. O século do corporativismo. Doutrina do corporativismo integral e puro. Rio de Janeiro: José Olimpio Editora, 1938.

MAZZA, Fábio. O idealismo prático de Roberto Simonsen. São Paulo: FIESP, 2004.

OLIVEIRA, Francisco de. A economia brasileira: crítica à razão dualista. Estudos CEBRAP. n 2, São Paulo, 1972.

SILVA, Sérgio. Expansão cafeeira e origens da indústria no Brasil. São Paulo: Alfa-Ômega, 1978

SIMONSEN Roberto. História econômica do Brasil. São Paulo: Cia Ed. Nacional, 1978. . \& GUDIN, Eugênio. A controvérsia do planejamento na economia brasileira. Rio de Janeiro: IPEA/INPES, 1977.

STOLCKE, Verena. Cafeicultura. Homens, mulheres e capital. São Paulo: Editora Brasiliense, 1986.

SOLA, Lourdes. Idéias econômicas, decisões políticas. São Paulo: FAPESP/EdUSP, 2000.

VIEIRA, Rosa Maria. O pensamento industrialista de Roberto Simonsen: análise de ideologia. Dissertação de Mestrado, História Econômica, Faculdade de Filosofia, Letras e Ciências Humanas, Universidade de São Paulo, 1988. 